resumption: A comparison of responding during and after differential reinforcement of other behavior. Paper presented at the meeting of the American Psychological Association, Honolulu, 1972.

Reuter, K. E., \& LeBlanc, J. M. Variable differential reinforcement of other behavior (VDRO): Its effectiveness as a modification procedure. Paper presented at the meeting of the American Psychological Association, Honolulu, 1972.

Topping, J. S., \& Larmi, O. K. Response elimination effectiveness of omission and two extinction training procedures. The Psychological Record, 1973, 23, 197-202.

Topping, J. S., Pickering, J. W., \& Jackson, J. A. The differential effects of omission and extinction following DRL pretraining. Psychonomic Science, 1971a, 24, 137-138.

Topping, J. S., Pickering, J. W., \& Jack son, J. A. Omission training effects following VI and FI pretraining. Psychonomic Science, 1971b, 24, 113-114.

Topping, J. S., Pickering, J. W., \& Jackson, J. A. Comparison of omission and extinction following FR reinforcement training.
The Psychological Record, 1972, 22, 221-224.

Uhl, C. N. Eliminating behavior with omission and extinction after varying amounts of training. Animal Learning \& Behavior, 1973, 1, 237-240.

Uhl, C. N., \& Garcia, E. E. Comparison of omission with extinction in response elimination in rats. Journal of Comparative \& Physiological Psychology, 1969, 69, 554-562.

Uhl, C. N., \& Sherrnan, W. O. Comparison of combinations of omission, punishment, and extinction methods in response elimination in rats. Journal of Comparative \& Physiological Psychology, 1971, 7.4, 59-65.

Zeiler, M. Eliminating behavior with reinforcement. Journal of the Experimental Analy sis of Behavior, 1971, 16, 401-405.

(Received for publication October 19, 1973.)

\title{
Attitude extremity as a determinant of attitude change in the forced-compliance experiment
}

\author{
DAVID R. SHAFFER* \\ University of Georgia, Athens, Ga. 30602
}

Ss, holding either extreme or moderate initial attitudes, wrote counterattitudinal essays in a test of contradictory hypotheses derived from Festinger's cognitive dissonance theory and Bem's self-perception theory. The results indicated, as predicted by dissonance theory, that Ss holding extreme initial attitudes showed more attitude change after counterattitudinal advocacy than Ss holding moderate initial attitudes. It was demonstrated that the results were not due to regression effects, to the production of differentially persuasive essays across the extremity conditions, or to the fact that Ss holding extreme attitudes had more "room for

*Requests for reprints should be addressed to David $R$. Shaffer, Department of Psychology, University of Georgia, Athens, Ga. 30602. Sponsored by Clyde Hendrick, who takes full editorial responsibility for its contents. change" in the direction of their essays than Ss holding moderate attitudes.

According to dissonance theory (Festinger, 1957; Brehm \& Cohen, 1962), a person who is induced to commit himself to an attitudinal position that is unambiguously inconsistent with his own private attitude will experience an aversive psychological tension, cognitive dissonance. The dissonance produced by a "forced-compliance" of this nature might easily be reduced if the person were simply to change his private attitude to make it consistent with his recent counterattitudinal advocation. Dissonance theory would predict that the more extreme the person's initial attitude, the greater the experience of dissonance resulting from counterattitudinal advocacy, and the greater the attitude change necessary to reduce that dissonance.

Bem $(1965,1967,1972)$ rejects the notion that an aversive mediator such as cognitive dissonance is 
necessary to explain the attitude change observed in forced-compliance experiments. Bem's self-perception theory maintains that, to the extent that internal cues are weak, ambiguous, or uninterpretable, individuals come to "know" their attitudes by inferring them from their overt behavior and/or the circumstances in which this behavior occurs. Accordingly, the person who has freely committed himself, for little or no reinforcement, to a counterattitudinal position infers his attitude toward the issue in question by asking himself, "What would my attitude have to be if I was willing to behave in this fashion in this situation?" Since he has no external justification for his actions (i.e., extrinsic rewards, etc.), he simply analyzes his behavior, coming to the quite rational conclusion that his "true" attitude must be consistent with his recent "counterattitudinal" behavior. Thus, self-perception theory argues that attitude change in forced-compliance experiments is mediated by a rational analysis of behavior, rather than an aversive drive state such as cognitive dissonance.

Although self-perception theory does not deal directly with attitude extremity as a determinant of attitude change, it seems reasonable that it could. Persons holding extreme attitudes are more ego-involved with those attitudes than persons holding moderate attitudes (Sherif \& Hovland, 1961), and are known to be more certain of their attitudinal positions as well (Cantril, 1946; Suchman, 1950). Thus, it seems reasonable to conclude that attitude extremity may serve as an internal discriminitive cue which increases the salience of one's attitudinal position; the greater the extremity, the greater the cueing function. This reasoning leads to the prediction that persons holding extreme initial attitudes, as compared to those holding moderate initial attitudes, are not as likely to infer their attitudes from external cues (i.e., their most recent behavior), and hence are less likely to change their attitudes after engaging in counterattitudinal advocacy. This latter prediction is at odds with the dissonance prediction regarding the effects of attitude extremity on attitude change, and thus places dissonance theory and self-perception theory in contention with one another. The present experiment provides a test of these contradictory predictions.

\section{METHOD}

\section{Subjects and Attitude Issue}

Eighty female undergraduates enrolled in an introductory psychology class at the University participated as Ss in two experimental sessions separated by an interval of 1 week. ${ }^{1}$ In the first session, Ss completed a questionnaire which assessed their attitudes toward a number of social and campus issues. Responses for each issue were obtained on 61-point horizontal scales labeled at 10-point intervals, from strongly disagree to strongly agree, with the label of uncertain at the scale midpoint of 30 . First session responses indicated that Ss generally agreed with the item "Women in our society are thought of and used primarily as sex objects," although they were clearly varied in the extremity of their agreement.

\section{Experimental Design}

The extremity of Ss' initial agreement with the "women as sex objects" target item was the variable of central interest. Ss were divided on the basis of their pretest attitudes into an extreme attitude group and a moderate attitude group. Half of the Ss in each of these groups were asked to write a counterattitudinal essay arguing that women in our society are not thought of and used primarily as sex objects (essay group), and half were not asked to write essays (no-essay control group), yielding a 2 by 2 factorial design.

\section{Procedure}

Upon their arrival at the second session, Ss who were to write essays were greeted by the $\mathrm{E}$ and presented with a set of written instructions informing them that the psychology department was continuing its study of the many different perspectives that people take to various social and campus problems. Ss were told that the issue of the week was the plight of women in contemporary society, and that they would be writing essays arguing either that women in our society are or are not primarily thought of and used as sex objects. Thus, Ss had a free choice as to the directions they might take in developing their essays.

To insure that Ss wrote counterattitudinal essays, an addendum sheet was inserted between the written instructions and the blank sheets provided for essay writing. The addendum stated that the researchers had collected more than enough arguments to support the idea that women in our society are thought of and treated as sex objects, and that arguments to the effect that women are not primarily regarded as sex objects were desperately needed. The addendum went on to state that the psychology department would appreciate it very much if people writing essays would write the strongest essays they could arguing that women in our society are not primarily regarded as sex objects. The addendum concluded by thanking Ss in advance for this cooperation.

After Ss had read all instructions, the E instructed them to write their essays. Ss were allowed $15 \mathrm{~min}$ to develop and transcribe their thoughts. Immdiately after essay writing, Ss again responded to the social and campus issues questionnaire which contained the "women as sex objects" target statement. Ss were then interviewed to assess their awareness of the experimental hypotheses or the intent of the essays, debriefed, and dismissed. Ss assigned to the control groups did not write essays in the second session. Their sole task was to complete the pre- and posttest attitude measures with a week intervening between sessions.

\section{RESULTS AND DISCUSSION Manipulation Check}

The initial attitudes of Ss in the four experimental conditions were subjected to a 2 by 2 analysis of variance to insure that attitude extremity was successfully varied across the two extremity conditions. The analysis revealed that extremity was successfully varied $(F=171.69$, $\mathrm{df}=1 / 76, \mathrm{p}<.001)$, as the mean initial attitude for the extreme attitude condition (50.03) was significantly more extreme than that of the moderate attitude condition (37.85). Ss who wrote essays did not differ from the no-essay control Ss in the extremity of their initial attitudes $(F=.20$, n.s. $)$, and the interaction was not significant.

\section{Attitude Change}

An attitude change score was determined for each $\mathrm{S}$ by calculating the difference between her pre- and posttest attitudinal responses. A negative difference score represents attitude change in the direction 
Table 1

Mean Attitude Change for the Four Experimental Conditions

\begin{tabular}{ccc}
\hline $\begin{array}{c}\text { Attitude } \\
\text { Extremity }\end{array}$ & Essay & $\begin{array}{c}\text { No-Essay } \\
\text { Control }\end{array}$ \\
\hline Extreme & -16.00 & -.55 \\
Moderate & -3.95 & -.75 \\
\hline
\end{tabular}

advocated by the S's essay. For the no-essay controls, a negative difference score represents change in the same direction as the essay condition and provides a check on the magnitude of regression effects. Table 1 shows the magnitude of attitude change for the four experimental conditions. A summary of the analysis of variance of the attitude change scores appears in Table 2.

An inspection of Table 2 indicates that all effects are significant. Ss who wrote essays showedi significantly more attitude change than no-essay control Ss $(F=$ 10.94 , df $=1 / 76, p<.005)$. Apparently, the attitude change shown by Ss who wrote essays represents more than a simple regression effect. Of greater interest is the finding that Ss holding extreme initial attitudes showed significantly more attitude change than their counterparts holding moderate initial attitudes $(F=$ $4.41, \mathrm{df}=1 / 77, \mathrm{p}<.05)$. This finding provides strong support for the dissonance prediction that the more extreme the $S$ 's initial attitude, the greater the dissonance resulting from counterattitudinal advocacy, and the greater the attitude change necessary to reduce that dissonance. The significant interaction $(\mathrm{F}=4.72 \mathrm{df}$ $=1 / 76, p<.05$ ) occurred due to the finding that Ss who wrote essays showed significantly more attitude change than no-essay control Ss only in the extreme attitude condition.

One criticism of the present study is that Ss with extreme initial attitudes necessarily have more "room for change" in the direction of their essays than Ss with moderate initial attitudes. Thus, differences in the absolute magnitude of attitude change for Ss at different levels of attitude extremity may partially reflect this scaling confound, rather than any real difference in dissonance-produced motivation to change initial attitudes. In order to control for the fact that Ss in the two extremity conditions had differential "room for change," a "percent of change possible" score was calculated for each $\mathrm{S}$ who wrote an essay by dividing her absolute attitude change into the amount of change she might have exhibited. The analysis of these "percent of change possible" scores reveals that, on a percentage

Table 2

Analysis of Variance of the Attitude Change Scores

\begin{tabular}{|c|c|c|c|}
\hline Source & $\mathrm{df}$ & MS & $\mathrm{F}$ \\
\hline $\begin{array}{l}\text { Essay Condition } \\
\text { (Essay vs No Essay) }\end{array}$ & 1 & 1739.112 & $10.94 \div$ \\
\hline $\begin{array}{l}\text { Attitude Extremity } \\
\text { (Extreme vs Moderate) }\end{array}$ & 1 & 702.122 & $4.41^{*}$ \\
\hline Interaction & 1 & 750.313 & $4.72^{*}$ \\
\hline Error & 76 & 159.048 & \\
\hline
\end{tabular}

basis, Ss with extreme initial attitudes again showed more attitude change ( $30.5 \%$ of that possible), than Ss with moderate initial attitudes $(5.8 \%$ of that possible) $(\mathrm{F}$ $=4.57, \mathrm{df}=1 / 38, \mathrm{p}<.05)$. It would appear, as predicted by dissonance theory, that Ss with extreme initial attitudes were under relatively greater pressure to alter their initial attitudes after counterattitudinal advocacy than Ss with moderate initial attitudes.

It might be argued that the relatively greater attitude change shown by Ss holding extreme initial attitudes was the result of a differentially persuasive set of essays, rather than a differential experience of dissonance. As a check on this possibility, two judges, blind as to Ss' experimental classification, rated the Ss' essays for persuasiveness. The ratings were made on 5-point Likert scales labeled at point intervals from -2 (not persuasive at all) to +2 (extremely persuasive). The obtained correlation for the judges' ratings of essay persuasiveness was +.83 . The ratings of neither judge would indicate that $\mathrm{Ss}$ in the two extremity conditions differed in the persuasiveness of their essays.

The finding that counterattitudinal advocacy produces more attitude change for Ss with extreme initial attitudes than for those with moderate initial attitudes is clearly inconsistent with the prediction derived from self-perception theory. However, this result is not necessarily inconsistent with the notion that attitude extremity serves a cueing function to increase the salience of one's initial attitude. If increasing extremity renders initial attitudes increasingly salient, then this increased salience may serve to remind the $S$ of the discrepancy between her initial position and the position taken in her essay, leading to greater experience of dissonance, and a greater need to change her attitude to reduce this dissonance. The results of the present study are consistent with this reasoning.

\section{REFERENCES}

Bem, D. J. An experimental analysis of self-persuasion. Journal of Experimental Social Psychology, 1965, 1, 195-218.

Bem, D. J. Self-perception: An alternative interpretation of cognitive dissonance phenomena. Psychological Review, 1967, 74, 183-200.

Bem, D. J. Self-perception theory. In L. Berkowitz (Ed.), Adrances in experimental social psychology. Vol.6. New York: Academic Press, 1072. Pp. 1-62.

Brehm, J. W., \& Cohen, A. R. Explorations in cognitive dissonance. New York: Wiley, 1962.

Cantrill. H. The intensity of an attitude. Journal of Abnormal \& Social Psychology, 1946, 41, 129-135.

Festinger, L. A theory of cognitive dissonance. Stanford: Stanford University Press, 1957.

Sherif, M., \& Hovland, C. I. Social judgment. New Haven: Yale University Press, 1961 .

Suchman, E. The intensity component in attitude and opinion research. In S. Stouffer, L. Guttman, E. Suchman, P. Lazarfeld, S. Star, and J. Clausen, (Eds.), Measurement and prediction. Princeton: Princeton University Press, 1950.

\section{NOTE}

1. Data were colledted from a total of $84 \mathrm{Ss}$. Two Ss were discarded for failing to write counterattitudinal essays. Two additional Ss were discarded because a postexperimental interview revealed that they were aware that the essays were designed to produce attitude change.

(Received for publication October 11, 1973.) 